\title{
Eigenschaften, Verbreitung und Bedeutung des nichtorganisirten activen Proteinstoffes.
}

Von

\section{Dr. Th. Bokorny.}

Dass in a e tive Eiwe is s t of fe in gewissen Pflanzentheilen sich in grosser Menge als Reservenahrungsstoffe anhäufen können, ist bekannt. Doch wurde nie die Frage erörtert und untersucht, ob nicht auch die a ctiven Proteinst of fe, aus denen das Protoplasma sich anfbaut, gespeichert vorkommen.

$O b$ actives Protein im nichtorganisirten Zustande überhaupt vorkommt oder nicht, wurde von 0 . L o e w und Verf. schon vor mehreren Jahren in bejahendem Sinne entschieden. Bei Spiro. gyren zeigte sich in vielen Fällen actives Protein an einem Zellorte, der frei ist von Zellorganen, in dem hier selr umfangreichen Zellsaftraume; der Zellsaft wies mehr oder minder grosse Mengen activen Proteins auf. Damit war die Frage nach der Existenz eines nicht organisirten activen Albumins erledigt; es gibt ein solches: Nicht immer wird also das von den Pflanzenzellen gebildete active Protein sofort zur Bildung oder Vergrösserung von Zellorganen (Organoiden), wie Chloroplasten, Vacuolenwand, Zellkern u. s. w., verwendet, sondern es tritt mitunter eine Ablagerung desselben ausserhalb der Organe ein.

$O b$ es auch in erheblichen Mengen gespeichert werden kann und ob das a ctive Protein ein verbreiteter Reservenahrungsst off, etwa ähnlich wie Stärke, Fett, inactives Eiweiss sei, das war noch zu prüfen.

Bezliglich des Begriffes "actives Protein" kann hier zunächst anf die bekannte Hypothese 0 . Loew's ${ }^{1}$ ) über die

1) In 0 . Loew und Th. Bok orny, chem. Kraftquelle, theoret. Theil. 
Entstehung und Constitution der zum Aufban der Zellen dienenden Eiweissstoffe verwiesen werden. Das active Albumin ist nach dieser Hypothese ein sehr labiler Stoff, in welchem die Labilität durch gleichzeitige Anwesenheit und Nebeneinanderlagerung von Aldehydund Amidgruppen bedingt wird. Bei den geringsten Eingriffen geht der labile Eiweissstoff in einen stabilen über, indem Aldehydund Amidgruppen in einander eingreifen und Atomverschiebung erleiden.

Auch hinsichtlich der friberen Versuche, welche von L o e w und Verf. zum Nachweis der Aldehydgruppen im activen Protein sowie zum Nachweis der $\Lambda$ midogruppen angestellt wurden, kann hier auf äItere Publikationen hingewiesen werden ${ }^{1}$ ). Zahlreiche Experimente wiesen thatsächlich auf jene vermuthete Constitution hin.

Bei manchen Objecten lässt sich der nichtorganisirte active Proteinstoff in Form von grossen glänzenden Kugeln, beziehungsweise Scheiben, zur Ausscheidung bringen, wenn man 0, lprocentige Lösung von Coffein oder 0,5procentige Lösung von Antipyrin auf sie einwirken lässt; jene Ausscheidungen wurden von $\mathrm{L}$ o e w und Verf. Prote os omen genannt; sie sind kugelig, wenn sie aus dem Zellsaft stammen, scheibenförmig (durch den Turgordruck), wenn sie im Cytoplasma entstehen.

Grosse Proteosomen, wie sie bei Spirogyren und manchen andern Pflanzen mit genannten Reagentien unter gewissen Bedingungen erzielt werden können, eignen sich besonders zum Studium der Eigenschaften des nichtorganisirten activen Albumins. An ibnen wurden darum in den letzten Jahren noch eine Reihe weiterer Beobachtungen ${ }^{2}$ ) iiber das active Albumin angestellt, auf die bier ganz kurz eingegangen sei, zur genaueren Charakteristik desselben.

1) Besonders wichtig in dieser Hinsicht sind auch die Arbeiten Loew's über Giftwirkung, worin gezeigt wurde, dass Körper, die leicht mit Aldehyden reagiren, allgemeine Gifte sind. Vergl. hieräber 0 . Loew, über Giftwirkung des Hydroxylamins, dieses Arch. 1885, p. 516 und O. Loew, natürl. System der Giftwirkungen, München 1893, p. 38 ff.

2) Zur Chemie der Proteosomen. Flora 1892, Beiheft, und botan. Centralblatt. 1893, Nr. 6. 
Fast angenblicklich nach Zugabe von Coffein - bei Anti. pyrin erfolgt die Einwirkung etwas träger - macht sich an giinstigen Objecten die Ausscheidung der Proteosomen bemerklich. Das Coffein dringt offenbar in geringer Menge momentan ein and schon minimale Mengen reichen aus, die merkwürdige Reaction hervorzurufen; schon mit 0,01procentiger Lösung erfolgt z. B. bei Crassulaceenblättern sehr bald Proteosomenbildung. Dass nicht viel Coffein zunächst eindringt, geht aus dem Unterbleiben gewisser anderer Erscheinungen hervor, die bei einigermaassen erheblicher Coffeinzufuhr sich sofort zeigen.

Der ausgeschiedene Eiweissstoff ist stark wasserhaltig, wie man an dem Zusammensehmelzen der Proteosomen und der daraus bervorgehenden fliussigen Beschaffenheit erkennt, sowie aus dem Zusammenschrumpfen bei der Gerinnung und Umlagerung. Nach einer ungefähren Schätzung wird bei der ersten Ansscheidung etwa die Hälfte bis zwei Drittel des Wassers ausgestossen, das iibrige Quellungswasser trennt sich erst bei der Gerinnung vom Eiweiss.

Die Einwirkung des Coffeins und Antipyrins auf das gelöste oder stark aufgequollene active Protein ist wobl am ehesten als eine Art Reiz aufunfassen. Durch den Contract mit Coffein poly. merisirt sich das active Albumin; es bilden sich grössere Molecïle, was mit einer Wasserausstossung verknüpft ist.

Die Zellen, in denen Proteosomenbildung stattgefunden hat, leben hänfig zunächst noch weiter; sie bleiben in ibren Functionen ungestört. Bei Spirogyren gelang sogar der Versuch, dieselben lange Zeit weiter leben za lassen, als die Proteosomen führenden Algen ans der Coffeinlösung in reines Wasser zurückversetzt wurden. Die Proteosomen wurden allmählich wieder aufgelöst.

Die Proteosomengeben sämmtliche mikrochemischen Eiweissreactionen, so dass also die Eiweissuatur derselben wohl nieht bestritten werden kann ${ }^{1}$ ). Man wählt zum Nachweis der Eiweissuatur zweckmässig grössere Proteosomen aus, d. h. solche, wie sie durch Zusammenschmelzen mehrer kleiner allmählich entstehen (ursprünglich kommen sie sämmtlich als kleine' Kügelchen zur Ausscheidung). Damit ist

1) Siehe hieriber insbesondere auch 0 . Loew und Th. Bok orny "Zur Chemie der Proteosomen", in Flora 1892, Beiheft. 
Millon's Reaction gut zu erhalten, wenn man die Objecte 8-10 Minuten in einer mit nicht zu wenig Kaliumnitrit versetzten ziemlich concentrirten Lösung von Mercurinitrat liegen lässt, um dem Reagens Zeit zu geben, in die (nun coagulirten) Kugeln einigermaassen einzudringen, und hierauf kurze Zeit zum Sieden erhitzt. Die $B$ i u retreactio n gelingt nicht, wenn man dazu die frischen Proteosomen anwendet, weil diese durch die Kalilauge des Reagens gelöst werden. Verwendet man die durch $0,2 \%$ Ammoniak $\mathrm{fi}$. xirte n Proteosomen, so gelingt die Reaction sehr gut; durch das Ammoniak gehen die Proteosomen in einen widerstandsfähigeren Zustand über, jedenfalls unter Bindung von Ammoniak. Man lässt anf die fixirten Proteosomen circa 12 Stunden lang bei $16-18^{\circ}$ eine mässig concentrirte Lösung von essigsaurem Kupfer einwirken und betupft die abgewaschenen Objecte mit sehr verdünnter Kalilauge; dabei nehmen sie eine intensive Violettfärbung an. Die Gelbfärbung mit Jod, die Blutlaugensalzreaction, Farbstoffspeicher u g gelingen - auch bei gerbstofffreien ${ }^{1}$ ) Proteosomen - recht gut.

Auch im Verhalten gegen kochendes Wasser, sowie gegen Alkohol zeigt sich Analogie mit den Eiweissstoffen; es tritt Coagulation ein. Wenn es auch richtig ist, dass man häufig die Coagula nicht mehr deutlich erkennen kann, sofern man Objecte mit Proteosomen direct in kochendes Wasser tancht, so werden doch die coagulirten Kugeln sehr schön sichtbar, wenn man vor dem Eintauchen dem kochenden Wasser noch 1-5\% Kocbsal\% zusetzt. Es ist ja eine bekannte Thatsache, dass sehr salzarme Eiweisslösungen beim Kochen nicht gerinnen und erst Zusatz von neutral reagirenden Salzeu sofortige Coagulation zu Stande bringt. Durch verdünten Alkohol werden die Proteosomen bald in den unlöslichen Zustand übergeführt, nach kurzem Verweilen in 10procentigem Alkohol sind die Kugeln trübe geworden und geschrumpft. Unter dem Mikroskop lässt sich die Umwandlung beim Behandeln mit 10 bis 20procentigem Weingeist an Spirogyren sehr schön verfolgen. Die gebildeten compacten

1) Häufig sind die Proteosomen gerbstoffhaltig, was von mancher Seite für derart wichtig gehalten wurde, dass man die wahre Natur der Proteosomen völlig verkannte. 
Massen oder auch Hoblkugeln werden weder von Wasser noch von absolutem Alkohol gelöst. Verfährt man dagegen so, dass man die Objecte sofort mit 80-90procentigem Alkohol behandelt, so wird das Coffein den Zellen so rasch entzogen, dass die meisten Proteosomen schneller sich wieder lösen ${ }^{1}$ ), als Coagulation erfolgen kann, wozu eben doch das Eindringen einer grösseren Alkoholmenge erforderlich ist. Man sieht dann nur an Stelle der grösseren Proteosomen ein dünnes Gerinnsel, kleinere scheinen völlig verschwunden zu sein; das feine Coagulum ist eben durch die ganze Zelle vertheilt.

Das Proteosomeneiweiss ist eine äusserst leicht veränderliche Substanz. Schon dureh das spontane Absterben der Zellen, in denen sie liegen, erleiden sie eine Umänderung, bald früher bald später, öfters schon wenige Minuten nach dem Tode.

Lässt man z. B. Spirogyren 5-6 Tage in einer 0,5procentigen Coffeinlösung liegen, so gehen einzelne Zellen der Fäden zu Grunde; diese heben sich unter dem Mikroskop scharf von den übrigen, noch lebenden ab. Sieht man nun dieselben genauer an, so zeigt sich durchweg auch ein total verändertes Aussehen der in ihnen enthaltenen Proteosomen. Sie sind viel weniger glänzend und durchscheinend als die unveränderten Proteosomen und zeigen 1 bis mehrere Höhlungen; die Consistenz ist von der flüssigen in die feste übergegangen. Ferner sind die ,abgestorbenen“ Proteosomen gegen Ammoniak indifferent, während die glänzenden flüssigen Proteosomen der noch lebenden Zellen Ammoniak binden (zu Amidoderivaten werden) und hierdurch andere Eigenschaften annehmen. Durch dieses Verhaltengegen Ammoniak ist jener Eiweissstoff der friseben Proteosomen scharf rom gew öhlichen Eiweissverschieden, welehes gegen verdüntes Ammoniak ganz indifferent ist.

Stoffe, welche schädlich auf die Zellen wirken, verändern auch auffallend rasch die Coffeinproteosomen. Manchmal geniigt es, eine 1 pro mille Es s i g s ä u relösung 15 Minuten lang wirken

1) Es wurde schon früher mitgetheilt, dass z. B. beim Eintauchen der Objecte in $25^{\circ}$ warmes Wasser die Lösung der Coffeinkugeln dureh Coffeinentziehung blitzschnell erfolgt. 
zu lassen, um die frischen glänzenden Proteosomen undurchsichtig zu machen. Eine 2procentige $\mathrm{Bl}$ a u s ä u re wandelt die frischen Proteosomen bald in Hohlkugeln um. Diamid, Formaldehyd A etber dunst, Stoffe, welche als Gifte bekannt sind, wirken in kurzer Zeit auch auf frische Proteosomen verändernd ein; das Aussehen der Proteosomena und ihr Verhalten gegen manche Reagentien ist dann wesentlich anders geworden.

Die frischen Coffein-Proteosomen besitzenintensives Silberabscheidungsvermögen, d. h. der Eiweissstoff derselben fällt aus den früher von 0 . Loew und Verf. angegebeneu höchstverdünnten Silberlösungen das Silber, er enthält eine Atomgruppe, die in den gewöhnliehen Eiweissstoffen nicht enthalten ist. Man hat zwar zu behaupten versucht, dass der Gerbstoff, der in den Proteosomen häufig mit eingeschlossen ist ${ }^{1}$ ), die Silberreduction bedinge. Allein der Einwand ist hinfällig, da der Gerbstoff aus Lösungen von der Verdünnung 1:100000 kein Silbermetall abzuscheiden vermag, und da ausserdem sicher erwiesen ist, dass gerbstofffreie Proteosomen ebenso intensiv reduciren wie gerbstoffhaltige. Man kann Spirogyren so zichten, dass sie zwar actives Eiweiss im Zellsaft entbalten, aber keinen Gerbstoff, - sie geben mit Coffein Proteosomenbildung, die Proteosomen scheiden Silber ab aus jenen höchst verdünnten alkalischen Auflösungen ${ }^{2}$ ).

Ausser durch Coffein und Antipyrin kann der active nichtorganisirte Eiweissstoff der Pflanzenzellen auch zur Ausscheidung gebracht werden durch sehr verdüntes $\mathrm{Kali}, A \mathrm{mmoniak}$, or$\mathrm{g}$ a $\mathrm{n}$ i s ch e Base $\mathrm{n}$ aller Art, überhaupt durch basische Stoffe. Doch ist der so ausgeschiedene Eiweissstoff nicht von jener grossen Aehnlichkeit mit dem belebten Stoffe selbst, nicht so wenig verändert, wie der durch Coffein oder Antipyrin ausgeschiedene; offenbar liegen dort innige Verbindungen des Eiweissstoffes mit den Basen vor, wäbrend die Coffeinproteosomen den activen leicht veränderlichen Eiweissstoff noch als solchen oder in äusserst locker

1) Nämlich wenn diese aus gerbstoffhaltiger Vacuolenflüssigkeit zur A.usscheidung kommen.

2) Siehe herüber: 0. Loew u. Th. Bokorny, über das Verhalten von Pflanzenzellen zu stark verd. alkal. Silberlösung, botan. Centralbl. 1893, Nr. 39. 
polymerisirtem Zustand erhalten. Uebrigens eignen sich auch Kali, Ammoniak ete. in manchen Fällen sebr gut zur Sichtbarmachung des activen Eiweissstoffes, d. h. zur Bewirkung der Proteosomenbildung, und werden daher gelegentlich Erwäbnung finden. Auch die Kali- und Anmoniak-Proteosomen besitzen das eben hervorgehobene Silberreductionsvermögen.

Der Proteosomen bildende Eiweiss tof $f^{1}$ ), ein Stoff rongrosser Labilität, findet sich nu a usser in Spirogyren noch in zahlreichen andern Pflanzen und Pflanzentheilen vor, of tingrosserMenge. $\mathrm{Er}$ ist ein Pflanzenstoff von weiter Verbreitung, soweit die bisherigen Untersuchungen reichen.

So kommt er reichlich in den Te ntakeln von Drosera vor. Die Ausscheidung desselben in glänzenden verschmelzenden Kugeln wurde von $\mathrm{Ch}$. Darw in "Aggregation" genannt und als Lebensreaction $^{2}$ ) erklärt, d. h. als eine Reaction, wclche an abgestorbenen Zellen auf keine Weise hervorgerufen werden kann.

Reizt man einen Tentakel auf irgend eine Weise - die Zahl der Reizmittel ist nach Darw in eine sehr grosse, ihre Art mannigfaltig - so treten mit Einbiegung desselben im Innern der Zellen auffallende Veränderungen ein. "Wenn ein Tentakel“, sagt D a rw in ${ }^{3}$ ), „einige Stunden, nachdem die Drüse durch wiederholtes Beriihren oder durch unorganische oder organische Theilchen, welche darauf lagen, oder durch die Aufsaugung von gewissen Fliissigkeiten gereizt worden war, untersucht wird, so bietet er ein gänzlich verändertes Ansehen dar. Die Zellen, anstatt mit homogener Flïssigkeit erfullit $z u$ sein, enthalten nun verschiedentlich geformte Massen von purpurner Substanz in einer farblosen oder beinabe farblosen Flüssigkeit suspendirt. Die Veränderung ist so augenfällig, dass sie durch eine schwache Lupe sichtbar ist und manchmal sogar mit blossem Auge; die Tentakeln haben nun ein geflecktes Ansehen, so dass ein in dieser Weise afficirter mit Leichtigkeit von andern

1) Damit ist nicht gemeint, dass es stets e in er oder e in und ders e l b e Eiweissstoff sei. L o e w und Verf. haben schon mehrmals hervorgehoben, dass wahrscheinlich viele Isomere hier in Betracht kommen können.

2) Eine solche ist sie selbstverständlich anch bei Spirogyra.

3) Insectenfressende Pflanzen, Uebersetzung von $\mathrm{C}$ a r u s, p. 34. 
unterschieden werden kann. Dasselbe Resultat erfolgt, wenn die Drüsen auf der Scheibe auf irgend eine Weise gereizt werden; denn ihren Inhalt wird man dann in einem zusammengeballten Zustand finden, obgleich ihre Drüsen noch keinen Gegenstand beriihrt haben." „Durch welche Ursachen auch der Process nur immer angeregt worden sein mag, er fängt innerhalb der Drüsen an und geht dann die Tentakeln hinunter. Er kann viel deutlicher in den oberen Zellen der Stiele als in den Drïsen beobachtet werden, da diese etwas undurchsichtig sind. Kurz nachdem die Tentakel sich wieder gestreckt haben, werden all' die kleinen Massen von Protoplasma wieder aufgelöst, und die purpurne Flüssigkeit in den Zellen wird wieder so homogen und durchsichtig wie sie vorher war."

Darwin hielt die geballte Substanz für Protoplasma! Denn er sagt: „Diese kleinen Massen verändern unaufhörlich ihre Form und Stellung und ruhen niemals. Eine einzige Masse theilt sich oft in zwei, welche sich nacher wieder vereinigen. Ihre Bewegungen sind ziemlich langsam und gleichen denen der Amoebe oder der weissen Blutkörperehen. Wir können daher folgern, dass sie ans Protoplasma bestehen." "Der Process der Zusammenballung ist ein lebendiger; ich meine damit, dass der Inhalt der Zellen lebendig und unverletzt sein muss, um in dieser Weise afficirt werden zu können.

Ganz zutreffend ist die Meinung D a r w in's bezüglich der Natur der sich ballenden Substanz zwar nicht; denn es handelt sich hier - wenigstens zum Theil ${ }^{1}$ - um nichtorgan i sirtes actives Albumin, während jedes Protoplasma organi s ir tes Albumin darstellt. Doch wurde von D a r w in mit Recht anf den Zusamwenhang jener Dinge mit dem Leben hingewiesen. Als chemisches Mittel, die Eiweisskugeln zur Ausscheidung zu bringen, wurde von $\mathrm{D}$ a $\mathrm{r}$ w i n hauptsächlich eine verdünnte Auflösung von kohlensaurem Ammoniak angewandt; nach D. geniigt schon die Aufsaugung von 0,0005 Milligramm durch eine Drüse, um im Laufe einer Stunde dentlich mikroskopisch bemerk-

1) Wie H. de Vries zeigte, tritt bei Drosera ausser der Ausscheidung von Eiweiss aus dem Zellsaft, häufig Contraction und Theilung der Vacuolenwand ein; die Theilvacuolen sehen den Eiweisskugeln oft zum Verwechseln ähulich. 
bare Ausscheidungen in den oberen Parenchymzellen des Stieles hervorzurufen. Verf. zeigte ${ }^{1}$, dass auch zahlreiche andere basische Stoffe dasselbe bewirken, und dass der Stickstoffgehalt des einwirkenden Stoffes nicht wesentlich ist, wie Darwin glaubte.

Die ausgeschiedenen Kugeln der Droserazellen geben alle Eiweissreactionen, ausserdem zeigen sie im frischen Zustande die leichte Veränderlichkeit, die oben bei Spirogyra beschrieben wurde, sie reduciren stark verdünnte alkalische Silberlösung und verlieren die Fähigkeit hierzu bei längerem Liegen der Präparate ete. Sie sind also als actives Albamin zu betrachten.

Als Ort der Ausscheidung ist hier der Z ellsaft, d. i. die Vacuole, zu nennen. In diesem ist das active Albumin ursprünglich gelöst oder aufgequollen. Doch kann man mit Kali $1: 1000$ oder Ammoniak $1: 10000$ in den gegen die Basis der Tentakel zu gelegenen Zelleu auch im $\mathrm{Cy}$ toplas ma Eiweisskugeln erhalten. Es ist da also auch im Cytoplasma nichtorganisirtes actives Albumin aufgespeichert.

Ausser in den Tentakeln ist bei D rosera das active Albumin im ganzen Blattparenchym sowie in der Epidermis der Blätter aufgespeichert, freilich in geringerer Menge als in den Tentakeln.

Eine andere insectenfressende Pflanze, Nepenthes phyll a $\mathrm{mph}$ or a, zeigt ebenfalls Eiweissspeicherung im Blatt, wie Verf. vor einigen Jahren ${ }^{2}$ ) fand. Hier sind die Blätter zu einer Kanne umgeformt, in welcher Verdauungsflüssigkeit abgesondert wird; in dieser Flïssigkeit findet man in der Regel gefangene und halbverdaute Thiere (Asseln und dgl.) vor.

Hebt man von dem Boden der Kanne (auf der Innenseite) Flächenschnitte ab mit der Vorsicht, dass die Epidermiszellen möglichst unverletzt bleiben, so kann man in der gesammten Epidermis durch verdïnntes kohlensaures Ammoniak oder freies Ammoniak oder noch besser durch 1 pro Mille gesättigte Coffeinlösung eine Ausscheidung von kleinen Kügelchen aus dem Zellsaft und Cytoplasma veranlassen, welche starkes Lichtbrechungsvermögen wie

1) Pringsh. Jahrb. XX, Heft 4.

2) „Ueber Agregation", Pringsh. Jahrb. f. wiss. Bot. Bd. XX. Heft 4 pag. 445 . 
die bei Spirogyra und Drosera beobachteten besitzen and wie diese rasch zu grösseren Kugeln zusammenfliessen. Nach Verlauf von etwa $1 / 4$ Stunde ist jede Epidermiszelle angefüllt mit grossen und kleinen glänzenden Kugeln, die sich auch in ihren chemischen Reactionen als identisch erweisen mit den bei Spirogyra beschriebenen.

Aehnlich verhält es sich mit der Epidermis an der Innenseite der Fangorgane von Darlingtonia californica ${ }^{1}$ ). Auch hier kann Aufspeicherung activen Albumins nachgewiesen werden; desgleichen bei Sarracenia purpurea ${ }^{2}$ ).

Bei Primula sinensis ist actives Albumin im Zellsaft der gesammten Epidermiszellen aufgespeichert und kann mit Coffeinlösung zor Anschauung gebracht werden.

Crocus vernus enthält nichtorganisirtes actives Albumin in der Narben-Epidermis; mit Coffeinlösung oder auch mit Kali oder Ammoniak von 1 pro mille scheidet sich dasselbe aus dem Cytoplasma aus.

In der Epidermis sowie den Driisenhaaren von $\mathrm{P}$ e I a r gon i u m - Stengeln und Blättern scheidet sich aus dem Zellsaft actives Albumin aus bei Einwirkung von 1 pro mille -Coffeinlösung oder -Kali- oder-Ammoniaklösung. Die Ausscheidungen werden mit alkalischer Silberlösung von 1:100000 tiefschwarz, erscheinen in abgestorbenen Zellen nicht etc.

Reichliche Aufspeicherung activen Albumins trifft man ferner in den Zellen der Staubfäden von Eugenia und Melaleuca, und in der Epidermis der Blithenorgane von Acacia.

Cyclamen europaeum lässt bei Einwirkung ron $1 \%$ Coffeinlösung auf die Epidermis der Blumenblätter Ausscheidung von Eiweisskugeln sowohl im Cytoplasma als im Zellsaft erkennen.

Die Crassulaceen Cotyledon, Echeveria, Sedum ete. haben an den Blättern eine subepidermale Schicht, welche reichlich actives Albumin im Cytoplasma gespeichert enthält und dieses beim Eindringen einer $1 \%$ Coffeinlösung in stark lichtbrechenden, leicht verschmelzenden Körperchen zur Ausscheidung bringt.

1) a. a. O. p. 447 .

2) Verf. in diesem Arch d. gesammt. Physiol. Bd. 45, p. 213. 
Der Blattstiel von Begon i a ist mit rothen Haaren besetzt, welche mit $1 \%$ Coffeinlösung actives Albumin ausscheiden.

Lässt man auf einen nicht allzu dïnnen Querschnitt durch das Blatt von Dionaea muscipula 1 pro mille Coffeinlösung einwirken, so zeigt sich Ausscheidung activen Albumins in den Epidermiszellen, ferner in Zellenzügen im Innern, welche vom Mittelnerv zum Rand des Blattes verlaufen.

Die jungen eben hervorbrechenden Blätter von $\mathrm{R} h$ e um zeigen in ibrer Epidermis reichliche Bildung von Eiweisskugeln mit $1 \%$ Coffeinlösung. In den Blüthen (Stiel, Perigon und Staubfäden) ruft Antipyrin wie Coffein Proteosomenbildung hervor.

In Längsschnitten durch diè Nectarien von $\mathrm{P}$ ass i flor a bringt 1 pro mille Ammoniak Ausscheidung activen Albumins in den Epidermiszellen hervor.

Die jungen Samenknospen von Impatiens Sultani zeigen mit $1 \%$ Coffeinlösung Eiweisskïgeleben in der Oberhaut; desgleichen mediane Längsschnitte durch den Blithenstiel in zahlreichen Zellen.

Junge Ahornblätter zeigen mit $1 / 2$ procentiger Antipyrinlösung starke Proteosomenbildung in der Epidermis. Desgleichen Knospenblätter von Crataegus oxyacantha. Staubfaden, Griffel und Blüthenboden von Acer enthalten viel actives Albumin.

Mimosa pudica enthält ebenfalls actives Albumin gespeichert in der Epidermis der Blättehen, ferner in den petiololi. Die Proteosomenbildung ist hier an jungen Blättern wegen deren geringer Dicke schon an ganzen Blattstiicken zu sehen, wenn man durch Einschnitte mit dem Rasirmesser dafür sorgt, dass das Reagens eindringen kann. Nach 12 stündigem Liegen sieht man in der das grïne Gewebe bedeckenden Epidermis deutlich die Proteosomen.

Helianthus-Keimlinge enthalten in den Reservestoffzellen der Cotyledonen gespeichertes actives Protein ( 0 . Loew).

Limnanth e mum zeigt in den eben hervorbrechenden Spitzen der Seitenwurzeln Proteosomenbildung.

Bei Rhododendron findet sich in der Oberhautschicht von Griffel und Narbe der Proteosomen gebende Stoff vor.

$\mathrm{C}$ ornusblütben zeigen viel actives Albumin in den Blüthenstielen und in den Perigonblättern. 
Sehr reich daran sind ferner die Narben von Salix; auch in der Bliithenstandsachse finden sich hier Zellen vor, die Proteosomenbildung ergeben; die Proteosomen treten deutlich im Cytoplasma auf. Auch in den männlichen Blïthenständen sowie in gewissen Zellen der Stammrinde ist actives Albumin gespeichert.

Forsythia suspensa gibt in der Epidermis der Staubfäden and der Griffel dentliche Proteosomenbildung.

Hoteia japonica enthält in Blithenstielen and Filamenten viel actives Albumin. Sy ring a wenig in den Blithenblättern, desgleichen die K i r s c h blüthe.

Die A p felblit the enthält sehr viel actives Albumin in den jungen Samenknospen.

Die weisse Malve enthält im jugendlichen Zustand kein actives Albumin, im ganz ausgewachsenen Zustande ebenfalls nicht, dagegen zeigt sie solches im balberwachsenen Zustande. Gerbstoff fehlt. (O. Loew.)

Prim u la zeigt Proteosomenbildung in Blumenkrone, Fruchtknoten, Griffel und jungen Samenanlagen. Desgleichen Gentiana in allen Blithentheilen sehr viel.

Euphorbia zeigt actives Albumin in Pistill und Stanbfäden.

Bei $\mathrm{Tax}$ us can adens is lassen sich an Längsschnitten durch den Zweiggipfel lang gestreckte Zellen auffinden, welche mit $0,1 \%$ Coffein deutliche Proteosomenbildung ergeben.

Scrofularia vernalis zeigt in den Blüthen etwas actives Albumin.

$\mathrm{Sc}$ bn e e b e e r e $\mathrm{n}$ entbalten im unreifen Zustande viel actives Albumin, im reifen keines melr. Gerbstoff feblt. (0. Loew.)

Mit 1 prozentigem Antipyrin erhält man starke Proteosomenbildung bei S o r b u s-A u c u paria - Blüthenknospen; desgleichen bei jungen P ap pel blättern.

E pidendron ciliare enthält in der Epidermis der gelben Blumenblätter actives Eiweiss; Alocasia in den Blattfleischzellen; Melianthus major im Blattstiel; A mor phophal lus Rivieri in den rothgefärbten Zellen des Blitthenschaftes; Viburnum rugos um ${ }^{1}$ ) in den Inflorescenzen.

1) Schon angeführt in diesem Arch., 1889, p. 214, in Th. Bokorny, "Zur Charakteristik des lebenden Pflanzenprotoplasmas." 
Von Pflanzen, in denen bis jetzt nie eine Ansammlung von activem Protein gefunden werden konnte, seien erwähnt: Sphäroplea annulina (eine Alge), Convallaria majalis, Ranunculus Ficaria, Tussilago Farfara, Anemone bepatica, Löwenzahn, Narcisse, Veronica purpurea, Bilbergia a moena u. s. w.

Da die obenerwähnten positiven Beispiele ganz beliebig herausgegriffen sind, lässt sich wohl annehmen, dass d a s $\mathrm{n}$ i c h torganisirte active Albumin noch in zahlreichen anderen Pflanzen aufgefunden werden kann und $\mathrm{zu}$ den $\mathrm{v}$ erbreitetsten Inhaltsstoffen der Pflanzenzellen gehört.

Welche physiologiscben Beziebungen lassen sich nun für das nichtorganisirte active Albumin vermuthen oder feststellen?

Die zunächst liegende Beziehung ist die, dass es zur Bildung: der Organoide des lebenden Plasmas verwendet wird, wenigstens bei denjenigen Pflanzenzellen, die noch des Wachsthums und der Theilung fähig sind. Wenn die Vermuthung richtig ist, so muss es durch Förderung des Wachsthums bei gleichbleibender oder noch besser verhinderter Eiweissbildung verbraucht werden. Andrerseits muss sich eine bedeutende Speicherung nachweisen lassen, wenn die Eiweissbildung mehr begünstigt wird als die Wachs thumsvorgänge.

Das lässt sich mit Hilfe der Coffeinreaction bestätigen. Bringt man eine geringe Spiropyrenmenge (Sp. Weberi) in mehrere Liter folgender (nitratfreien) Lösung:

$$
\begin{aligned}
& 0,05 \% \text { Calciumsulfat } \\
& 0,02 \% \text { "Calciumbicarbonat } \\
& 0,02 \% \text { Magnesiumsulfat } \\
& 0,005 \% \text { Monokaliumphosphat } \\
& \text { Spur Eisenchlorid, }
\end{aligned}
$$

und untersucht die Spirogyren nach mehrwöchentlichem Stehen im zerstreuten Tageslicht bei $16-18^{0}$, so finden sich nur noch geringe Spuren von activem Albumin vor. Es fehlen die Stickstoffverbindungen, Eiweissneubildung ist also unmöglich und die wachsenden Zellen sind lediglich auf das bereits gespeicherte ac- 
tive Protein angewiesen, das allmählich verbraucht wird. Eine bedeutende Speicherung dagegen gelingt, wenn man bei Gegenwart aller Nährsalze besonders die Menge des Kaliumnitrats vermehrt, indem dadurch die Kohlenstoffassimilation angeregt wird und die nun in grösseren Mengen disponibel werdende Glucose auch die Dissociation und Reduction der Sulfate und Nitrate, resp. die Eiweissbildung energisch befördert; man kann so bei Anwendung einer eiweissarmen Spirogyra schon binnen einigen Wocben sebr reichliche Aufspeicherung activen Albumins erzielen. Eine solche Nährlösung ist z. B.

$$
\begin{aligned}
& 0,05 \% \text { Kaliumnitrat } \\
& 0,03 \text { "Calciumnitrat } \\
& 0,005 \text { " Magnesiumsulfat } \\
& \text { 0,005 " Monokaliumphosphat } \\
& \text { Spur. Eisenchlorid. }
\end{aligned}
$$

In dieser Lösung ging bei Spir. nitida und Sp. majuscula die Eiweissbildung so rasch vor sich, dass keine erhebliche Stärkemenge gespeichert wurde, sondern alles gebildete Kohlehydrat in Form von Glucose zur Eiweissbildung diente; Coffein rief nun enorm starke Ausscheidung hervor.

Ferner lässt sich beobachten, dass Temperaturverhältnisse erheblichen Einfluss auf die Menge des gespeicherten activen Proteins austiben. Die Temperatur beeinflusst eben das Wachsthum; bei warmer Witterung geht dasselbe rascher vor sich als bei kalter, in Folge dessen findet man bei ersterer (ceteris paribus) weniger Protein gespeichert als bei letzterer. Von dieser Thatsache kann sich jeder uberzengen, der Spirogyren zu allen Jahreszeiten sammelt und dieselben mit 1 pro Mille Cofteinlösung prüft.

Das gespeicherte active Protein ist also bei Spirogyren nachgewiesenermaassen e in Reservestoff, welcher beim Wachsthum anmittelbar zum Aufbau der Organe dient.

Bei Spirogyren wird das überschüssige active Protein in denselben Zellen, in denen es gebildet wurde, abgelagert, und in Zeiten lebhaften Wachsthums oder geringer Neubildung wieder verbraucht. Der Ort der Bildung und des Verbrauches können hier nicht zweifelhaft sein; ebensowenig die Art des Verbrauches. Die 
Spirogyren bestehen ans lauter gleichartigen assimilirenden Zellen; die Eiweissbildung findet also hier sicher in denselben Zellen statt, in welchen assimilirt ${ }^{1}$, d. i. Kohlehydrat aus Kohlensäure gebildet wird.

Aus dem gelegentlichen Verschwinden in Spirogyrenzellen ergibt sich ein Fingerzeig für die Bedeutung des nichtorganisirten activen Proteins in andern Fällen, wo die Verwendung nicht experimentell klargelegt ist.

Besonders hervortretend ist in den angeführten Beispielen das Vorkommen desselben in Blüthenorganen, wie Staubfäden, Griffeln, Blithenstielen, Perigonblättern u. s. w. In den Blithen wird viel Eiweiss gebraucht zur Bildung der Pollenkörner und Samenanlagen; aus diesem Grunde findet eine lebhaftere Zuströmung ${ }^{2}$ ) des activen Albumins nach den Blüthen statt. Die Ausbildung der für die Fortpflanzung wichtigen Theile wird auf diese Weise gesichert.

Aehnlich dürfte es sich mit dem Vorkommen activen Proteins in jungen Blättern verhalten; die weitere Entwicklung derselben soll dadurch sichergestellt werden.

Junge Früchte, wie die unreifen Schneebeeren, sammeln actives Protein auf, um Material für: das weitere Wachsthum zu haben; das Verschwinden desselben beim Reifen der Frucht weist direct auf diese Bedeutung hin.

Nun weisen freilich auch völlig ansgewachsene und keine neuen Zellen producirende Organe, wie die ausgewachsenen Blätter der Crassulaceen gespeichertes actives Protein auf; die speichemden Zellen liegen unmittelbar unter der Epidermis. Vielleicht soll damit für den Fall einer Verletzung der Blattoberfläche Bildungsmaterial für neue Zellen bereitgestellt sein.

Was die Vertheilung des gespeicherten activen Proteins nach Geweben betrifft, so ist die Bevorzugung der Epidermis von grossem Interesse. Kein lebendes Gewebe ist ausgeschlossen von der Function, actives Protein zu speichern; doch tritt die Speicherung

1) In dem beschränkten botanischen Sinn.

2) Die Wanderung des unveränderten activen Proteins im Pflanzenkörper ist möglich durch die jetzt fast überall nachgewiesenen Plasmaverbindungen zwischen den Zellen. 
mit überwiegender Häufigkeit in der Epidermis ein. Sollte hier vielleicht die Bildung desselben besonders reichlich stattfinden (aus zugefübrten Kohlehydraten und stickstoffhaltigen Substanzen)? Da auch die Kerne hier meist ungewöhnlich gross ausgebildet erscheinen und die Eiweissbildung möglicherweise im Zellkern vor sich geht, so dürte jene Vermuthung etwas für sich haben.

Vielleicht ist auch die verhältnissmässig weite Entfernung der Epidermis von den Leitbuindeln und die dadureh bedingte geringe Abfuhr zum Theil Schuld daran, dass in diesem Gewebe besonders bäufig eine Speicherung activen Proteins angetroffen wird.

Das Vorkommen activen Proteins in der Epidermis der fle ischverdauenden Pflanzen scheint ferner auf eine Beziebung zur Fermentbildung hinzuweisen. 